\title{
Spatial modelling and mapping of teen birth rates in Taiwan in the period 1995-2010
}

\author{
Ying-Chih Chuang, ${ }^{1}$ Ting-Wu Chuang, ${ }^{2}$ Hsing Jasmine Chao, ${ }^{1}$ Kuo-Chien Tseng, \\ Kun-Yang Chuang \\ ${ }^{1}$ School of Public Health; ${ }^{2}$ Department of Molecular Parasitology and Tropical Diseases, \\ School of Medicine, Taipei Medical University, Taipei City, Taiwan
}

\begin{abstract}
Geographical variations in teen birth rates (TBR) still persist despite controlling for contextual factors. The aim of this research was to identify spatial patterns of TBR in Taiwan and to examine spatial relationships among different contextual factors. Using townships as the unit of analysis $(N=359)$, this research used social and demographic variables for the years 1995, 2000, 2005 and 2010 and conducted spatial modelling of TBR. Geographical maps of TBR were presented, and Local Indicator of Spatial Autocorrelations was used to identify TBR clustering. Comparisons were made between ordinary least-squares models and spatial lag models, in which township-level TBRs were regressed on other township-level contextual characteristics. Our study found that townships with a high TBR were mostly in eastern, central and some southern regions of Taiwan, while townships with a low TBR were in the vicinity of metropolitan areas. The
\end{abstract}

Correspondence: Kun-Yang Chuang, School of Public Health, Taipei Medical University, $250 \mathrm{Wu}-H$ sing St., Taipei 11031, Taiwan. Te1.: 886.2.27361661 ext. 6522 - Fax: 886.2.27384831.

E-mail: adinma@tmu.edu.tw

Key words: Teen birth rate; Geographic Information System; Spatial modelling; Taiwan.

Contributions: YCC and KYC designed the study and wrote the manuscript. TWC, HJC, and KCT collected data and conducted analyses. All authors participated in the editing of the manuscript.

Conflict of interest: the authors declare no potential conflict of interest.

Funding: this study was funded by the Ministry of Science and Technology, Taiwan (Grant No.: MOST 104-2119-M-038-003 to Dr. Ying-Chih Chuang).

Received for publication: 19 April 2018.

Revision received: 16 July 2018.

Accepted for publication: 14 August 2018.

(C) Copyright Y-C. Chuang et al., 2018

Licensee PAGEPress, Italy

Geospatial Health 2018; 13:700

doi:10.4081/gh.2018.700

This article is distributed under the terms of the Creative Commons Attribution Noncommercial License (CC BY-NC 4.0) which permits any noncommercial use, distribution, and reproduction in any medium, provided the original author(s) and source are credited. significant spatial lag indicated that townships would have a higher expected prevalence rate if adjacent townships have had higher rates. Results also indicated that the percentage of aborigines and the percentage of college-educated people were consistently associated with TBR over the years. Interventions aimed at reducing TBR in Taiwan should consider the presence of spatial correlations and should incorporate neighbouring townships.

\section{Introduction}

The teen birth rate (TBR) has dramatically declined across Taiwan in the past two decades changing from 17 births per 1,000 teens in 1990 to 4 births per 1,000 teens in 2010 (Government, 2016). The country has a population of nearly 23 million distributed over a geographical area of about $36,193 \mathrm{~km}^{2}$ (13,974 sq mi). Despite its small geographical size, local variations in TBRs still persist with declines exhibiting marked regional differences. In 2010, the TBRs for some rural townships in Taiwan were about 10 times higher than those in metropolitan areas such as Taipei City (Government, 2016). Most prior studies on teen pregnancy and birth focus on individual- and interpersonal-level risk factors and prevention programmes emphasizing knowledge and personal decision-making rather than contextual influence on teen pregnancy (Maness and Buhi, 2016). Still, identification of contextual risk factors related to TBR, as well as its geographical distribution, is important in providing clues to causal pathways of increasing gaps in TBRs among regions (Salazar et al., 2010; Gunaratne et al., 2015). Some sociological theories have suggested possible explanations regarding spatial heterogeneity in TBRs (Shaw and McKay, 1969; Shoff and Yang, 2012). Possible explanations include differences in community norms, collective efficacy, health service provision and the employment environment. Moreover, previous studies have identified population density, divorce rate, education and healthcare resources as significant contextual factors (Sampson et al., 1997; Sampson and Raudenbush, 1999; South and Crowder, 2010). Population density was negatively related to the general birth rate in population studies, but was also related to elective abortions among teenagers (Lutz et al., 2006). The community-level divorce rate has been linked to the prevalence of adolescent risk behaviours, such as violence, substance use and teen pregnancy (Carlson et al., 2014). The racial or ethnic composition of an area may also be related to the TBR, since it has been shown that race and ethnicity differ with regard to age of the first birth and also reflect the fact that marginalized populations are more likely to live in disadvantaged neighbourhoods and therefore exposed to risk behaviours (Shirley and Long, 2004; Mollborn, 2010). These aforementioned contextual factors could further affect how indi- 
viduals utilize local health services, including contraceptive use, or how they react to stress and unsafe environment, even how they manage teen pregnancy and births (Mollborn, 2010). In this study, we identified spatial patterns of TBRs using a geographical information system and spatial modelling to examine spatial relationships among different contextual factors (Yao et al., 2012). Most previous ecological studies focused only on the influence of factors in the immediate residential community. However, communities are embedded in a larger system of geographical areas, and it is possible that adolescents who live in surrounding communities can share social and institutional ties, which can affect local norms of teen pregnancy (South and Crowder, 2010). This has been recognized in prior studies studying the diffusion effects of teen pregnancy due to social interaction of people living in nearby areas (South and Crowder, 2010). The objective of this study was to assess the influence of adjacent or otherwise proximate communities on TBR with the expectation that findings could provide additional insights on factors influencing TBR that may lead to new approaches in designing interventions.

\section{Materials and Methods}

This study was a repeated cross-sectional study for the years 1995, 2000, 2005 and 2010, using township, county-level city, and districts as the units of analysis. Briefly, the administrative structure in Taiwan, from large to small in terms of population size, has the following geographical hierarchy: special municipality, provincial city, county-level city, and township. To provide a basis of comparison, the minimum population sizes for special municipalities and provincial cities were 1,250,000, and 500,000, respectively. Special municipalities and provincial cities can be further divided into districts, usually with a population size of $<200,000$. The county-level city, which is one level below the provincial city, has a minimum population of 150,000 but no more than 500,000 , while townships have populations less than 150,000 . Hence, for this research, townships, county-level cities and districts were used as the administrative units of analysis since they were similar with regard to population size. Many health and social service sources are allocated at this level, and previous research have pointed out that heterogeneity in socioeconomic conditions, racial composition and health outcomes is present within these geographical units (Hung et al., 2009). In total, 359 townships, county-level cities and districts (hereafter referred to as townships) were included in the analysis.

\section{Data source and measurements}

The outcome variable was TBRs, defined as live births per 10,000 women aged 15 19 years and log-transformed for normality. The explanatory variables included population density (number per $\mathrm{km}^{2}$ ), percentage of the aboriginal population, percentage of the elderly population, percentage of the college-educated population, number of physician per 10,000 persons, social welfare spending per person and the divorce rate, which was calculated as the number of divorced and separated persons over the number of people aged $\geq 15$ years. Data used to generate these variables were retrieved from multiple sources of official government statistics: Household Registration Statistics, City and County Statistics and Census (Ministry of Finance, Taiwan, 2016). The Household Registration Statistics provided data on the age and sex distribution of the population within townships. The City and County Statistics provided data on births, marriages and divorces, as well as healthcare resources and social expenditures, while the Census provided information on educational attainment and ethnicity.

\section{Analysis}

We used ArcGIS (ESRI, Redlands, CA, USA), to create maps and conduct analysis of spatial TBR patterns according to Tatem et al. (2014), and Global Moran's I (Cressie, 1993) to examine spatial autocorrelations of the TBRs (Uthman, 2008). Since Global Moran's I does not identify individual clusters, Local Indicator of Spatial Autocorrelation (Anselin, 1995) was used to identify particular townships clustering with high and low TBRs. This approach was specifically used to identify significant townships where both the target township and its neighbours had high values (high-high hot spots) or both had low values (low-low cold spots). In the multivariate analysis, we compared both the Ordinary Least Squares (OLS) models and spatial lag models in which townshiplevel TBRs were regressed on other township-level demographic and socioeconomic characteristics (Vogt et al., 2014). The decision that spatial lag models were selected instead of spatial error models was based on the Lagrange-multiplier test (Anselin and Bera, 1998) and the robust Lagrange-multiplier test (Anselin and Bera, 1998). Both tests suggest that the spatial lag models are more significant than the spatial error models. Spatial lag models were estimated through an autoregressive process of the dependent variable with the following equation:

$$
\mathrm{Y}=\rho \mathrm{WY}+\mathrm{X} \beta+\varepsilon
$$

where $\rho$ is the spatial autoregressive parameter, $\mathrm{W}$ a weighted matrix that expresses a form of spatial association among each pair

Table 1. Description of contextual factors and teen birth rates by year in Taiwan.

\begin{tabular}{|c|c|c|c|c|}
\hline Variable & Year 1995 & Year 2000 & Year 2005 & Year 2010 \\
\hline Teen birth rate (\%o) & 22.5 & 20 & 12 & 4 \\
\hline Population density (no./km²) & 692.9 & 701.5 & 675.3 & 654.5 \\
\hline People $>65$ years old $(\%)$ & 8.5 & 9.9 & 11.3 & 12.4 \\
\hline Physician density (no./10,000 inhabitants) & 4.3 & 4.8 & 5.6 & 5.6 \\
\hline People divorced or separated (\%) & 2.7 & 4.2 & 4.3 & 6.7 \\
\hline Aborigines (\%) & 0.3 & 0.3 & 0.5 & 0.6 \\
\hline People with college education (\%) & 7.6 & 10.7 & 13.2 & 19.4 \\
\hline Social spending (NT\$/per person) ${ }^{a}$ & 789.8 & $1,515.4$ & 848.3 & 971.5 \\
\hline
\end{tabular}

aUS\$1 New Taiwan (NT) $\$ 30$. 
of clusters, $\mathrm{X}$ a matrix of exogenous explanatory variables with an associated vector of regression coefficients $\beta$ and $\varepsilon$ a vector of normally distributed random error terms. The fitness of the model was assessed using the Quasi-likelihood Information Criterion (James et al., 2017). The Variance Inflation Factor (James et al., 2017) was used to check for multicollinearity in the model. The significance level of alpha was set to 5\%. Prior studies suggested that 5 or 10 years can be a reasonable time difference to assess the change between two time points in larger area analyses (i.e., county, state or country), and hence multivariate analyses were separately conducted for the years 1995, 2000, 2005 and 2010 for comparative purposes with the aim to observe changes in the influence of predictors over time (Chuang et al., 2013).

We originally intended to include data of 2015 as well; however, this was not done since TBRs and their geographical distribution steadied after 2010, and the introduction of some major changes in Taiwan's administrative structure after 2010, especially with reference to township boundaries.

\section{Results}

Table 1 shows the level of TBRs and contextual variables for the four years under study. The average TBR rates per township declined from 22.5 per 1,000 adolescent women in 1995 to 20 in 2000 , and then continued to decline to reach as low as 4 in the year 2010. In the same period, all indicators investigated, with the exception of population density, showed an increasing trend. Social expenditures increased significantly in the year of 2000 because of the establishment of the emergency relief fund for a serious earthquake (Jiji, 1999).

Descriptive maps were constructed based on quintiles using the TBRs of 1995 as the standard (Figure 1). Even if the TBR rates in general decreased significantly over the study period, some townships in the eastern and central regions of the country still had high TBRs in 2010, indicating the presence of geographical variations. Indeed, the values of the Global Moran's $I$ of the TBRs were 0.587 in 1995, 0.520 in 2000, 0.456 in 2005, and 0.258 in 2010, which revealed significant spatial autocorrelations as evidence of a non-random distribution of TBRs in Taiwan. The estimated local
Moran's $I$ values are shown in Figure 2. In 1995, high TBRs (hotspots) were mostly seen in eastern, central, and some southern regions of Taiwan, and low TBRs (coldspots) in the proximity of the cities of Taipei and Kaohsiung. Over the years, especially in 2010, the coldspots strongly decreased in size, while the hotspots remained in the central, eastern and southern regions of Taiwan. However, they too appeared to be shrinking in size.

Table 2 shows Spearman's correlation coefficients between TBRs and other characteristics in 1995. Social welfare spending was the only variable not significantly associated with TBR. The correlation coefficients ranged from small $(r=-0.030)$ to large $(r=0.757)$. Table 3 summarizes results of the OLS and spatial lag models for TBRs by year. The R-squared values showed that spatial lag models explain more variance in TBRs than OLS models, which was evident for all four years studied. The spatial lag models explained $77.1 \%, 71.3 \%, 71.5 \%$ and $54.2 \%$ of the variation in TBRs for 1995, 2000, 2005, 2010, respectively (compared to $75.6 \%, 70.3 \%, 70 \%, 52.3 \%$, respectively, using OLS models). The Akaike Information Criterion (Bozdogan, 1987) and Log likelihood statistics also showed better model fit for spatial lag models compared to the OLS models. For the OLS model in 1995, percentage of elderly $(\beta=0.0393)$, divorce rates $(\beta=0.1293)$, percentage of aborigines $(\beta=0.0089)$, population density $(\beta=-0.0252)$, social welfare

Table 2. Spearman correlations of contextual factors and teen birth rates in 1995 in Taiwan.

\begin{tabular}{lc}
\hline Variable & Teen birth rate \\
Teen birth rate (\%0) & 1.000 \\
Population density $\left(\mathrm{no} . / \mathrm{km}^{2}\right)$ & $-0.359^{*}$ \\
\hline People $>65$ years old (\%) & $0.148^{*}$ \\
Physician density (no./10,000 inhabitants) & $-0.268^{*}$ \\
\hline People divorced or separated (\%) & $0.394^{*}$ \\
Aborigines (\%) & $0.757^{*}$ \\
\hline People with college education (\%) & $-0.555^{*}$ \\
Social spending & -0.030 \\
\hline${ }^{*}<0.05$. &
\end{tabular}

Table 3. Multivariate analysis of contextual factors on teen birth rates by year in Taiwan.

\begin{tabular}{|c|c|c|c|c|c|c|c|c|}
\hline \multirow[b]{2}{*}{ Model } & \multicolumn{2}{|c|}{ Year 1995} & \multicolumn{2}{|c|}{ Year 2000} & \multicolumn{2}{|c|}{ Year 2005} & \multicolumn{2}{|c|}{ Year 2010} \\
\hline & OLS $^{a}$ & Slag $^{b}$ & OLS $^{a}$ & Slag $^{b}$ & OLS $^{a}$ & Slag $^{b}$ & OLS $^{\mathrm{a}}$ & Slag $^{b}$ \\
\hline Population density (no. $\left./ \mathrm{km}^{2}\right)$ & $-0.0252 *$ & $-0.0188^{*}$ & $-0.0371^{*}$ & $-0.0304 *$ & $-0.0208 *$ & $-0.0138 *$ & -0.0103 & -0.0041 \\
\hline People $>65$ years old $(\%)$ & $0.0393^{*}$ & $0.0309^{*}$ & $0.0274^{*}$ & $0.0227^{*}$ & $0.0318 *$ & $0.0228 *$ & 0.0112 & 0.0058 \\
\hline Physician density (no./10,000 inhabitants) & -0.0012 & -0.0017 & -0.0032 & $-0.0032 *$ & -0.0026 & -0.0030 & 0.0000 & -0.0002 \\
\hline People divorced or separated (\%) & $0.1293^{*}$ & $0.0886^{*}$ & $0.0767^{*}$ & $0.0645^{*}$ & 0.0109 & 0.0035 & 0.0390 & 0.0212 \\
\hline Aborigines (\%) & $0.0089 *$ & $0.0081^{*}$ & $0.0059 *$ & $0.0053^{*}$ & $0.0101^{*}$ & $0.0084^{*}$ & $0.0129 *$ & $0.0110^{*}$ \\
\hline People with college education (\%) & $-0.0547^{*}$ & $-0.0489 *$ & $-0.0388 *$ & $-0.0363^{*}$ & $-0.0525^{*}$ & $-0.0474 *$ & $-0.0397^{*}$ & $-0.0363^{*}$ \\
\hline Social spending (NT\$/per person) ${ }^{\mathrm{a}}$ & $-0.3450^{*}$ & -0.2095 & 0.0141 & 0.0129 & -0.0507 & -0.0208 & 0.1082 & 0.1322 \\
\hline Spatial lag term & & $0.185^{*}$ & & $0.145^{*}$ & & $0.202 *$ & & $0.221^{*}$ \\
\hline $\mathrm{R}^{2}$ & 0.7564 & 0.7711 & 0.7038 & 0.7131 & 0.7009 & 0.7151 & 0.523289 & 0.5420 \\
\hline Akaike Information Criterion & 245.481 & 227.856 & 323.927 & 316.067 & 426.66 & 414.176 & 677.008 & 668.21 \\
\hline Log likelihood & -114.741 & -104.928 & -153.963 & -149.034 & -205.33 & -198.088 & -330.504 & -325.105 \\
\hline
\end{tabular}

${ }^{*} \mathrm{P}<0.05 ;{ }^{\mathrm{a} O L S}$, Ordinary Least Squares; ${ }^{\text {} S}$ Spatial Lag model. 
1995

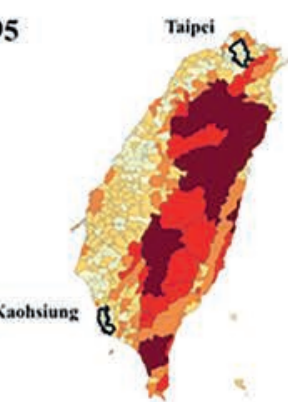

2000

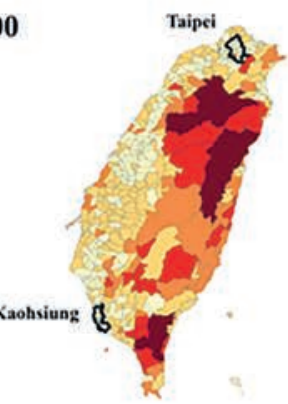

2005

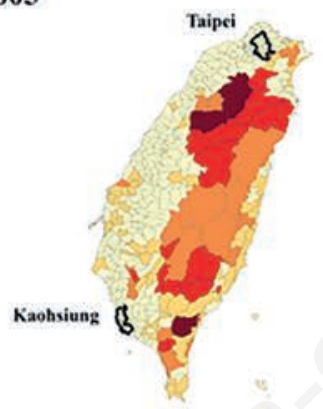

2010

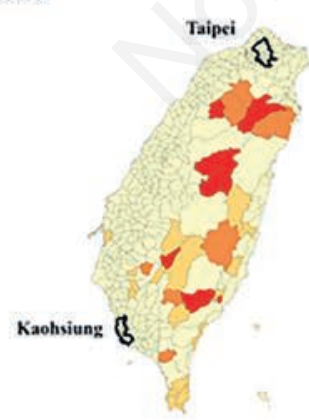

Main city

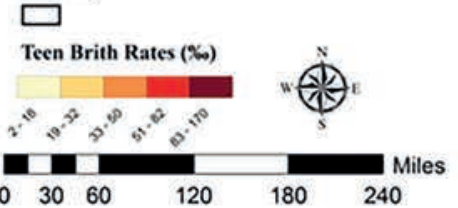

1995

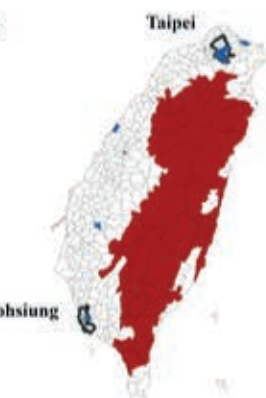

2000

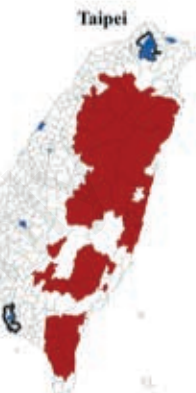

2005

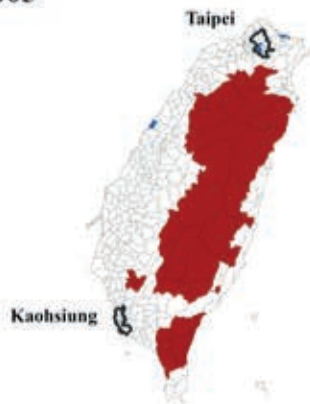

2010

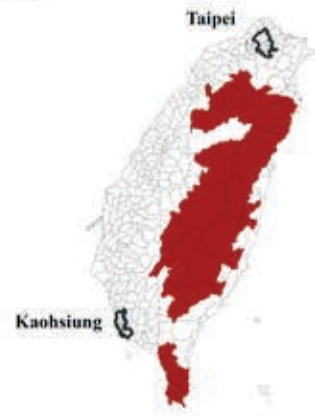

Cluster

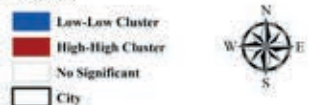

No Stennificant

at?

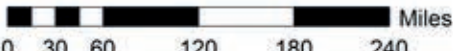

Figure 1. Teen birth rates in Taiwan by year.

Figure 2. Local Moran's I values of teen birth rates in Taiwan by year. 
spending $(\beta=-0.345)$ and percentage of college-educated people $(\beta=-0.0547)$ were found to be associated with TBRs. Compared to the OLS model, the spatial lag model showed similar results in 1995 with the exception of social welfare spending. In the 2000, 2005, and 2010 models, the variables that were significant in the OLS model remained significant in the spatial lag model as well but were smaller in magnitude. Overall, fewer township-level factors were significantly associated with TBRs in 2010 compared to models from earlier years (Table 3). Only two variables, the percentage of aborigines and the percentage of college-educated people were consistently associated with TBR over all the years covered by the analysis. The spatial lag term was statistically significant in every spatial lag model, which indicates that a township had a higher expected prevalence rate if adjacent townships also had higher rates.

\section{Discussion}

This study revealed that spatial lag models could estimate the relationship between township-level risk factors and TBR more accurately than the OLS model, indicating that a township would have a higher expected prevalence rate if adjacent townships also had a higher rate. In Taiwan, the educational system may have played a crucial role in linking TBRs across township boundaries. Based on test scores, teenagers may end up attending schools in nearby townships or in other counties, instead of within their own local community. Cross-township peer groups develop quickly and hence, values and subcultures, such as attitudes towards sexual behaviour and teenage pregnancy could disseminate across township borders readily. Overall, the extent of cross-township social exchange among teenagers in Taiwan is probably much more frequent than that arising due to other educational systems, e.g., those where most students attend local high schools. Cross-township peer groups and social exchange may enhance the spatial correlations of TBRs found in Taiwan.

Another interesting finding was that the influence of community-level predictors on TBRs has diminished over the years. This study revealed that health resources, such as the physician ratio and social welfare spending, had stronger associations with TBRs in earlier years, but became non-significant in later years. The implementation of the National Health Insurance program in 1995 has increased access to health care in rural areas, which has ameliorated the problem of inequality of health and welfare resources among townships. This possibly explains why we found that resource-related factors were no longer significantly associated with TBRs in Taiwan after 2000.

As previously reported, TBRs in Taiwan show geographical variations with the highest TBRs found in the central and eastern regions of Taiwan (Hung et al., 2009). Over the years, the influence of demographic factors, as well as health and welfare resource factors, have tended to decrease. However, the percentage of aborigines and the percentage of higher-educated people continue to be significantly associated with TBRs. There are 16 different aboriginal tribes in Taiwan (Lee et al., 2013) and these people all face difficulties in current Taiwanese society. Their average household income is $<40 \%$ of that of the general population and they have a 8-year lower life expectancy compared to the general population. The anthropological literature points out that most aboriginal tribes have the custom of early marriage, and exhibit characteristics of matriarchal societies (Tsai and Wong, 2004). Moreover, a large majority of aboriginals are Christians and tend to have an unfavourable predisposition toward abortion. It appears that once they become pregnant, adolescent aboriginal females, compared to other non-aboriginals, are more likely go through with the birth rather than have an abortion. Similar differences between adolescent Hispanic and white females in the US are reported (Shirley and Long, 2004).

A low community education level, particularly in Taiwan, is traditionally regarded as an important contextual disadvantage $(\mathrm{Li}$ and Chuang, 2009). Confucian culture places great emphasis on higher education and the cost of higher education in Taiwan is quite inexpensive (Chou and Ching, 2012). Hence, communities with a low percentage of college-educated people are likely to be deprived of educational resources, which creates a vicious circle where general aspirations, expectations for higher education and skilled job positions are too low to retain or attract college-educated persons. In such communities, conventional norms cannot be maintained, local basic organizations collapse and a high proportions of people become isolated from the job network system, resulting in a higher likelihood of adolescent risk behaviours (Wilson, 1987).

This study has several limitations. The selection of indicators was limited by the availability of data from government sources and hence, the research may have excluded some relevant variables previously identified to be associated with TBRs, such as the unemployment rate, which was not available at the township level. Inclusion of the unemployment rate would provide better control of economic factors in the analysis. Second, this was a repeated cross-sectional study, and therefore, the causal relationship between township-level variables and TBRs should be interpreted with caution. In particular, relationships of social spending and the divorce rate with TBRs could be bi-directional. Finally, the results can only be generalized at the township level.

\section{Conclusions}

Two factors predicted TBRs in the different time periods consistently: the percentage of aborigines and the percentage of the higher-educated population, the former negatively (higher rates) and the latter positively (lower rates). Significant associations of TBRs among neighbouring townships were observed, even after controlling for other contextual factors.

Future interventions to reduce TBRs in Taiwan would likely be more successful if they considered the presence of spatial correlations and treated neighbouring townships jointly, rather than focusing on individual townships.

\section{References}

Anselin L, 1995. Local Indicators of Spatial Association - LISA. Geogr Anal 27:93-115.

Anselin L, Bera A, 1998. Spatial dependence in linear regression models with an introduction to spatial econometrics. In: Ullah A, Giles D, eds. Handbook of Applied Economic Statistics. New York, NY: Marcel Dekker. pp 237-289.

Bozdogan H, 1987. Model selection and Akaike's Information Criterion (AIC): the general theory and its analytical extensions. Psychometrika 52:345-70.

Carlson DL, McNulty TL, Bellair PE, Wattsd S, 2014. 
Neighborhoods and race/ethnic disparities in adolescent sexual risk behavior. J Youth Adol 43:1536-49.

Chou C, Ching G, 2012. Taiwan education at the crossroad: when globalization meets localization. New York, NY: Palgrave Macmillan.

Chuang YC, Sung PW, Chao HJ, Bai CH, Chang CJ, 2013. A longitudinal ecological study of the influences of political, economic, and health services characteristics on under-five mortality in less-developed countries. Health Place 23:111-21.

Cressie NAC, 1993. Statistics for Spatial Data. New York: Wiley.

Gunaratne S, Masinter L, Kolak M, Feinglass J, 2015. Change in population characteristics and teen birth rates in 77 community areas: Chicago, Illinois, 1999-2009. Public Health Rep 130:372-9.

Hung WW, Chuang KY, Chuang YC, 2009. Effects of townshiplevel characteristics on teenage birth rates in Taiwan. Taiwan J Public Health 28:491-502.

James G, Witten D, Hastie T, Tibshirani R, 2017. An introduction to statistical learning. 8th ed. New York: Springer.

Lee CS, Liao SF, Liu IC, Lee WC, Cheng AT, 2013. Incidence of first onset alcohol use disorder: a 16-year follow-up in the Taiwanese aborigines. Soc Psychiatry Psychiatr Epidemiol 48:955-63.

Li YS, Chuang YC, 2009. Neighborhood effects on an individual's health using neighbrohood measurements developed by factor analysis and cluster analysis. J Urban Health 85:5-18.

Lutz W, Testa M, Penn D, 2006. Population density is a key factor in declining human fertility. Population Environ 289:69-81.

Maness SB, Buhi ER, 2016. Associations between social determinants of health and pregnancy among young people and pregnancy among young people: a systematic review of research published during the past 25 years. Public Health Rep 141:8699.

Ministry of Finance, Taiwan, 2016. Available from: http://www.fdc.gov.tw/dp.asp@mp=5

Mollborn S, 2010. Predictors and consequences of adolescents' norms against teenage pregnancy. Sociol Quart 51:303-28.

Salazar LF, Bradley ELP, Younge SN, Daluga NA, Crosby RA, Lang DL, DiClemente RJ, 2010. Applying ecological perspec- tives to adolescent sexual health in the United States: rhetoric or reality? Health Edu Res 25:552-62.

Sampson RJ, Raudenbush SW, 1999. Systematic social observation of public spaces: A new look at disorder in urban neighborhoods. Am J Sociol 10:603-51.

Sampson RJ, Raudenbush SW, Earls F, 1997. Neighborhoods and violent crime: a multilevel study of collective efficacy. Science 277:918-24.

Shaw CR, McKay HD, 1969. Juvenile delinquency and urban areas: a study of rates of delinquency in relation to differential characteristics of local communities in American cities. Chicago: University of Chicago Press.

Shirley R, Long R, 2008. Teengage preganacy in Nueces Couty Texas: breaking the myth. Econ Pulse 1:2-3.

Shoff C, Yang TC, 2012. Spatially varying predictors of teenage birth rates among counties in the United States. Demogr Res 27:377-418.

South SJ, Crowder K, 2010. Neighborhood poverty and nonmarital fertility: spatial and temporal dimensions. J Marriage Fam 72:89-104

Tatem AJ, Campbell J, Guerra-Arias M, de Bernis L, Moran A, Matthews Z, 2014. Mapping for maternal and newborn health: the distributions of women of childbearing age, pregnancies and births. Int J Health Geogr 13:2.

Tsai YF, Wong TK, 2004. Aboriginal adolescents' pregnancy in eastern Taiwan. West J Nurs Res 26:595-608.

Uthman OA, 2008. Geographical variations and contextual effects on age of initiation of sexual intercourse among women in Nigeria: a multilevel and spatial analysis. Int J Health Geogr $7: 27$

Vogt V, Siegel M, Sundmacher L, 2014. Examining regional variation in the use of cancer screening in Germany. Soc Sci Med 110:74-80.

Wilson WJ, 1987. The Truly disadvantaged: the inner city, the underclass, and public policy. Chicago: University of Chicago Press.

Yao J, Murray AT, Agadjanian V, Hayford SR, 2012. Geographic influences on sexual and reproductive health service utilization in rural Mozambique. Appl Geogr 32:601-7. 